\title{
AEROMONAS SPP.: FATORES DE VIRULÊNCIA E PERFIS DE RESISTÊNCIA A ANTIMICROBIANOS E METAIS PESADOS
}

\author{
L.J.S. Peixotoํㅜ, M.C.A. Sá ${ }^{2}$, L.A. Gordiano ${ }^{2}$, M.M. Costa ${ }^{2}$ \\ ${ }^{1}$ Instituto Federal de Educação, Ciência e Tecnologia do Sertão Pernambucano, Estrado do Tamboril, s/noㅡ, \\ CEP 56200-000, Ouricuri, PE, Brasil. E-mail: lucianajatoba@hotmail.com
}

\section{RESUMO}

\begin{abstract}
As bactérias do gênero Aeromonas spp. são considerados como patógenos oportunistas carreadores de múltiplos fatores de virulência. O fenômeno da resistência aos antimicrobianos e metais pesados constitui outro problema, podendo ocorrer por diferentes fatores, dentre eles o uso indiscriminado de agentes antimicrobianos, poluição ambiental e a presença de mecanismos de resistência, como bombas de efluxo, sendo que muitos destes podem ser transmitidos por elementos genéticos móveis como os plasmídeos. O objetivo desse artigo é fazer uma revisão bibliográfica sobre os fatores de virulência, resistência a antimicrobianos e metais pesados, bem como os mecanismos que podem intervir nessa resistência e sua transferência entre bactérias do gênero Aeromonas. Os estudos dos fatores envolvidos no mecanismo de surgimento da resistência, aliado aos estudos de biologia molecular, fornecem subsídios para elaboração de métodos de controle e profilaxia dessas enfermidades de impacto aos organismos aquáticos, seres humanos e meio ambiente.
\end{abstract}

PALAVRAS-CHAVE: Micro-organismos, fatores de virulência, plasmídeo, bomba de efluxo.

\begin{abstract}
AEROMONAS SPP.: VIRULENCE FACTORS AND RESISTANCE PATTERNS TO ANTIMICROBIAL AND HEAVY METALS. Bacteria from Aeromonas spp. genus are considered as opportunistic pathogens that can carry many virulence factors. The resistance phenomenon to antimicrobial drugs and heavy metals is another problem and may occurs by several factors, as the indiscriminate usage, environmental pollution and the presence of resistance determinants as efflux pumps, being many of them transmitted by genetic mobile elements as plasmid. The purpose of this article is to review about the virulence factors, antimicrobial and heavy metal resistance, as well as the mechanisms that can help its transfer among Aeromonas genus bacteria. Studies of the resistance mechanisms associated to molecular biology could produce information about control and prophylaxis methods to this disease of impact on aquatic organisms, man and environment.
\end{abstract}

KEY WORDS: Microorganisms, virulence factors, plasmid, efflux pump.

O aumento na prevalência de enfermidades bacterianas em peixes leva a perdas significativas na produção aquícola, afetando o desenvolvimento econômico do setor em muitos países. As bactérias do gênero Aeromonas são um dos principais causadores de perdas na piscicultura constituindo-se em importante patógeno encontrado na água, solo, alimentos, fezes humanas e animais (GRAM et al., 1999). Estas bactérias são importantes agentes de gastroenterites transmitidas aos seres humanos pelo contato e consumo de carne e água contaminadas (AbDullah et al., 2003).

Por muitos anos, a taxonomia de Aeromonas foi desconhecida e depois de significativas revisões foi esclarecida. A técnica de amplificação do DNA por
PCR (Reação em Cadeia pela Polimerase) fornece uma ferramenta altamente sensível e específica para a detecção destes micro-organismos através de seus produtos de secreção (CASCón et al., 1996).

As espécies de Aeromonas secretam muitas proteínas extracelulares, incluindo amilase, quitinase, elastase, aerolisina, nuclease, gelatinase, lecitinase, lipase e protease. Estas proteínas são conhecidas como fatores de virulência que causam doenças em peixes e humanos (NAM; JoH, 2007).

$\mathrm{O}$ uso indiscriminado de antimicrobianos para o controle de doenças ou como promotores de crescimento aumenta a pressão da seleção sobre os micro-organismos, levando naturalmente ao aumento da resistência bacteriana. Em muitos sistemas

${ }^{2}$ Universidade Federal do Vale do São Francisco, Petrolina, PE, Brasil. 
aquáticos, resíduos de metais contaminantes possui significância, ocasionado em parte pelas atividades industriais e de mineradoras (MATYAR et al., 2009). A grande contaminação do meio ambiente com metais funciona como agente seletivo na proliferação de resistência a antibióticos. Diferentes níveis e tipos de contaminações por metais sugerem mecanismos no processo de co-seleção dessa resistência (BAKERAustin et al., 2006).

As bactérias possuem diferentes mecanismos de resistência antimicrobiana, dentre esses, a bomba de efluxo, que são proteínas integrantes da membrana plasmática que agem bombeando as drogas do meio intracelular para o meio extracelular, antes mesmo que elas exerçam sua função (PIDDOCK, 2006).

Além da proliferação das bactérias resistentes após a morte das consideradas sensíveis às drogas, há também a possibilidade da transferência dos genes de resistência a outras bactérias que nunca foram expostas a tal antibiótico (VERSCHUERE et al., 2000). Ressalta-se que no ambiente aquático a troca de genes de resistência é estimulada devido à fácil movimentação dos micro-organismos e elementos genéticos móveis como os plasmídeos (SмiтH et al., 2008). Assim, diversos genes para resistência a metais pesados são codificados em plasmídeos, sendo relatada a existência de uma associação direta da resistência bacteriana aos antimicrobianos e metais pesados. Tal fato poderia ser explicado pela vantagem ambiental da co-seleção destas informações em um único plasmídeo, especialmente quando a bactéria estiver num ambiente poluído (YATES et al., 2004).

\section{Gênero Aeromonas e sua importância em saúde pública}

Aeromonas spp. são bastonetes gram-negativos, de vida livre, anaeróbios facultativos, sendo antes classificadas junto ao Vibrio spp.e Plesiomonas shigelloides na família Vibrionaceae, porém, estudos genéticos evidenciaram a necessidade de sua reclassificação em uma família própria, Aeromonadacea (GHENGHESH et al., 2008). Colwell et al. (1986) propuseram esta reclassificação do gênero Aeromonas, uma vez que estas apresentam características filogenéticas distintas daquelas encontradas na família Vibrionaceae.

A identificação de espécies de Aeromonas spp. tem sido uma questão de discussão devido à sua diversidade fenotípica e genotípica. Neste sentido, a amplificação do gene rRNA $16 S$ através da PCR é uma forma boa e rápida de avaliar a identidade de todas as espécies conhecidas (Borrell et al., 1997). Beaz-Hidalgo et al. (2010) comprovaram que os testes moleculares são mais sensíveis que os métodos bioquímicos de identificação de bactérias deste gênero, em particular o sequênciamento de genes constitutivos, como rpo D, o qual se mostra como uma importante ferramenta para o futuro em particular para confirmar a identificação de $A$. hydrophila. CASTRO-EsCaRpulli et al. (2003) confirmaram a identificação fenotípica de 82 isolados de Aeromonas de peixes destinados ao consumo humano no México por PCR, através da amplificação do rRNA16S, como também GHATAK et al. (2007) identificaram 53 cepas de Aeromonas de múltiplas origens de importância médica através da sua amplificação e em um estudo objetivando avaliar presença de fatores de virulência e sensibilidade antimicrobiana os 19 isolados deágua mineral também foram identificados por PCR com amplificação deste gene (SCOARIS et al., 2008).

NAWAz et al. (2006) fizeram a caracterização taxonômica de Aeromonas spp. isolada de peixes através de provas moleculares pela técnica de PCRRFLP (Análise de Polimorfismo de Fragmentos de Restrição) e, dos 81 isolados, 23 foram identificados como A. hydrophila, 7 A. trota, 6 A. caviae, 42 A. veronni e 3 A. jandaei.

Para os peixes, as bactérias do gênero Aeromonas spp. são consideradas bactérias oportunistas, organismos patogênicos facultativos e manifestam-se em hospedeiros enfraquecidose/ou atacados por outros agentes etiológicos, sendo considerados invasores secundários, estabelecendo-se ao mesmo tempo em que outras infecções bacterianas, virais, parasitárias ou em decorrências de problemas nutricionais ou de estresse (Pavanelli et al., 2008). Cinco são as espécies de importância clínica: A. hydrophila, A. caviae, A. sobria, A. veronii e A. schubertii. Podem ser isoladas de répteis, anfíbios, peixes e de algumas aves. As espécies A. hydrophila e A. salmonicida são importantes agentes patogênicos para peixes e para a saúde pública, por multiplicar-se e produzir exotoxinas em temperaturas de refrigeração.

Existem controvérsias sobre a patogenicidade da Aeromonas em humanos, mas o seu isolamento em fezes de indivíduos com diarreia e ausência de outro patógeno sugere seu papel como causador da doença, bem como nos casos de infecções generalizadas (FoOD..., 2004). AltwEGG; Geiss (1989) associaram Aeromonas a uma diversidade de infecções como septicemia, meningite, celulite, ectima gangrenoso, pneumonia, peritonite, conjuntivite, úlcera decórnea, osteomielite, artrite supurativa, miosite, infecção do trato urinário, endocardite, entre outros. Em indivíduos saudáveis os sintomas mais comuns são gastroenterites e os imunocomprometidos podem apresentar severos quadros de septicemia.

A. hydrophila foi o único patógeno isolado de fezes diarreicas de uma criança de um ano de idade no México, sendo a cepa identificada por provas bioquímicas e métodos genéticos e confirmada sua capacidade de produção de enzimas extracelulares relacionadas com virulência, proteases, lípases e hemolisinas (Aguilera-Arreolaet al., 2009). A grande 
dispersão da Aeromonas spp. no meio ambiente pode ser a hipótese mais provável de infecções por consumo de alimentos eágua contaminada, mesmo sem grandes surtos terem sidos relatados. Aeromonas é um patógeno que produz vários fatores de virulência, por esse motivo a infecção pode se apresentar complexa e multifatorial (CHOPRA; Houston, 1999).

A presença de bactérias do gênero Aeromonas nos alimentos tem sido demonstrada. Normalmente destacam-se os alimentos que durante sua industrialização entraram em contato com a água, a qual é tida como habitat natural das diversas espécies e principal fonte decontaminação(BIZANI; BRANDELLI, 2001). Esses microorganismos são cada vez mais reconhecidos como patógenos entéricos e possuem fatores de virulência que contribuem para o desen-cadeamento da doença (NIHAL; SEDA, 2010). Estes autores isolaram 73 cepas de origem ambiental e alimentar com a finalidade de comparar suas carac-terísticas fenotípicas e de patogenicidade, sendoidentificadas cepas potencialmente patogênicas, demonstrando ser um risco significativo para a saúde pública. Rall et al. (1998) relataram que $48 \%$ das amostras de peixe pintado coletado em São Paulo estavam contaminadas com Aeromonas spp., tendo uma maior frequência de $A$. caviae, seguida de A. hydrophila e A. sobria.

\section{Fatores de virulência}

As hemolisinas, citotoxinas, fosfolipases, DNase e habilidade de aderência às células epiteliais são diferentes produtos extracelulares biologicamente ativos presentes em espécies do gênero Aeromonas importantes como fatores de virulência (SCOARIS et al., 2008). As suas enterotoxinas produzem várias proteases que causam danos teciduais e auxiliam no estabelecimento da infecção. $O$ trato gastrintestinal parece ser a principal fonte de infecção de Aeromonas spp. em humanos, acarretando uma doença com diarreica de curta duração variando desde diarreia aquosa, semelhante a cólera, até um quadro clínico de disenteria típico com fezes sanguinolentas e com muito muco, podendoocasionar síndromehemolítica urêmica esporadicamente(TRABUlsi; AlterTHUM, 2004).

A virulência das Aeromonas émultifatorial, incluindo fatores de aderência, como S-layer e lipopolissacarídeos, sideróforos e uma matriz de exoenzimas e exotoxinas, ou seja, aerolisina/hemolisina, lipases, proteases, entre outros (WONG et al., 1998). SEN; RODGERS (2004) avaliaram a presença de seis fatores de virulência de cepas de Aeromonas isoladas na água de tratamento municipal nos Estados Unidos encontrando elastase (ahyB), lipase (pla/lip/lipH3/ alp-1) flagelina A e B (flaA e flaB), e a presença de enterotoxinas, act, alt e ast, identificando uma grande variedade de combinações desses genes em diferentes linhagens da mesma espécie e um isolado de
A. hydrophilla foi positivo para a presença dos seis fatores analisados.

SCOARIS et al. (2008), em estudos realizados no Estado do Paraná/Brasil, isolaram a partir de água de torneira, água mineral e de poço artesiano, 19 cepas de Aeromonas spp. para investigar sua capacidade de produção de diferentes fatores de virulência tais como, hemolisinas, formação de biofilmee produção de adesinas. A maioria dos isolados apresentou atividade hemolítica e, no geral, os isolados apresentaram-se hábeis para invadir células epiteliais. O consumo de água sem tratamento adequado pode ser considerado como um possível veiculador de Aeromonas spp., bem como os fatores de virulência presentes podem agravar o quadro da doença.

De 408 pacientes admitidos com gastrenterite aguda em dois hospitais do Rio Grande do Sul, em 27 $(6,6 \%)$ foram isolados Aeromonas com maior prevalência em lactantes e crianças. Genes (aerA-aerolisina/ hemolisina, ahp A-serina-protease, satA-glicerofosfolipidio-colesterol aciltransferase, lipA-lipase, e ahyBelastase) efatores de virulência (atividade hemolítica, proteolítica, lipolítica e formação de biofilme) foram identificados na maioria dos isolados de A. hydrophila e $A$. veronii biotipo sobria, com frequências menores em A. caviae (GuERra et al. 2007).

BIZANI; BRANDELLI (2001) identificaram que espécies de A. hydrophilla e A. sobria isoladas a partir de água de abatedouro bovino foram positivas nas reações dehemólise ehemoaglutinação. As amostras de água foram provenientes de abastecimento e escoamento, sendo considerado como um fator contaminante, já que a água de abastecimento é utilizada na lavagem das carcaças.

CAstro-Escarpulli et al. (2003) avaliaram 82 isolados de Aeromonas spp. a partir de 250 amostras de peixes congelados quanto a presença de fatores de virulência importantes para o desenvolvimento de uma infecção bacteriana, por meio da PCR, sendo observada a presença dos genes aerolisina/hemolisina, lipases extracelular (lip, lipH3, pla, plc e GCAT), proteasee DNase. Paraidentificaçãofenotípica foram realizadas as provas de vermelho congo, aderência celular (HEp-2), bem como a atividade hemolítica, proteolítica, lipolítica, atividade de nuclease, sendo as amostras positivas.

KINGOMBE et al. (2010) usaram um novo método de PCRmultiplex para detecção detrês genes de virulência (act/alt/ast) em 537 isolados de Aeromonas a partir de alimentos e os isolados apresentaram-se com aspecto multifatorial para genes de virulência, evidenciando assim contaminante de risco a saúde pública.

\section{Resistência aos antimicrobianos}

$\mathrm{Na}$ atual situação não existe uma relação de antimicrobianos adequados para tratar as condições 
específicas das doenças dos peixes. As diferenças fisiológicas entre as espécies de peixes e ambientes aquáticos são muito maiores do que para os animais terrestres. Isto interferena forma de desenvolvimento da doença e de seu quadro clínico que pode variar de uma espécie pra outra ou na mesma espécie em diferentes condições ambientais, com necessidades farmacocinéticas específicas (SMITH et al., 2008).

Em virtude da grande diversidade do setor aquícola, o uso de agentes antimicrobianos não pode ser generalizado em todas as situações. Devem-se considerar os aspectos do antimicrobiano, tais como dosagens, uso racional, espécies cultivadas, bem como a farmacodinâmica e a farmacocinética da droga a ser utilizada. Em relação aos agentes empregados na aquicultura mundial existem diferenças nos dados de um país para outro, mesmo com essas variações os agentes antimicrobianos mais utilizados pertencem ao grupo das tetraciclinas, das sulfonamidas e das quinolonas de primeira e segunda geração (GuARDABASSI et al., 2010).

$\mathrm{O}$ uso indiscriminado de antibióticos na aquicultura leva ao desenvolvimento de bactérias com característica de múltipla resistência aos antimicrobianos (FraPPAOla; Guest, 1986). Mutações e outras alterações genéticas no genoma bacteriano geram a base da resistência antimicrobiana. Essas alterações genéticas podem ocorrer de diversas maneiras, incluindo mutação espontânea e aquisição de elementos genéticos móveis, tais como plasmídeos e integrons (GuARDABASSI et al., 2010).

Č́̇̌̌EK et al. (2010) verificaram que os isolados de Aeromonas de duas espécies de carpas mostraram alta resistência à oxitetraciclina, usando a técnica de PCR para avaliar a presença do gene tet que confere resistência à tetraciclina, sendo detectado em $40 \%$ $(48 / 121)$ dos isolados. IsHidA et al. (2010) identificaram a presença de genes de resistência à tetraciclina em 26,3\% (72/274) de bactérias gram-negativas isoladas de água de sistemas de piscicultura no norte do Egito. Nawaz etal. (2006), após identificarem espécies de Aeromonas por PCR-RFLP, avaliaram a presença de 5 tipos de gene tet (A-E) por PCR multiplex; o gene tetE apresentou-se dominante sobre os demais, sendo identificado em $90 \%$ dos isolados (73/81).

Aeromonas spp. isoladas a partir de sistemas de aquicultura na Africa doSul apresentaram resistência a betalactâmicos, porém, sensibilidade às cefalosporinas de segunda e terceira geração. 78,3\% foram resistentes às tetraciclinas, com a amplificação do gene tet $\mathrm{ABC}$ em $70,3 \%$ e o gene tet $\mathrm{DEH}$ em $54,1 \%$ dos isolados (JACOBS; CHENIA, 2007).

MejDi et al. (2010) determinaram a sensibilidade in vitro de Vibrio spp. e Aeromonas spp. isoladas de água do mar e mexilhões, frente 12 antimicrobianos usando o método de Kirby-Bauer, e a maioria dos isolados mostrou-se resistente a pelo menos dois agentes e a ampicilina apresentou a maior porcentagem de resistência.

EVANGELISTA-BARRETO et al. (2010) isolaram sete espécies diferentes de Aeromonas no Rio Cocó no Ceará/Brasil e testaram a resistência frente a oito antibióticos, sendo que $60 \%$ apresentaram resistência a pelomenos um antimicrobiano. Múltipla resistência a antibióticos também foi observada em $A$. caviae, $A$. sobria e $A$. veronii bv. sóbria e a $A$. caviae apresentou o maior índice de múltipla resistência, sendo resistente a quatro antibióticos.

Entre os patógenos entéricos, esseéum problema grave nos países em desenvolvimento, onde existe uma alta taxa de gastrenterites e uso inadequado de antibióticos. Essa resistência é particularmente relevante na patogenicidade da Aeromonas spp. que, além da clássica aos $\beta$-lactâmicos, múltiplas resistências vêm sendo observadas (GUERRA et al., 2007). A maioria das Aeromonas spp. é resistente à penicilina, ampicilina e carbenicilina. Em geral, são sensíveis às cefalosporinas, aminoglicosídeos, tetraciclinas, cloranfenicol, sulfametoxazol-trimetoprim e quinolonas. Como as síndromes diarreicas são autolimitantes, a terapêutica antimicrobiana é questionável e indicada nos casos mais graves, envolvendo pacientes imunodeprimidos ou com septicemias (Trabulsi; Alterthum, 2004).

BIZANI; BRANDELLI (2001) testaram 32 antibióticos em quinze isolados de Aeromonas a partir de água de abatedouro de bovinos e a A. hydrophilla mostrou-se menos sensível aos antibióticos testados. Todos os isolados apresentaram resistência aos betalactâmicos, sozinho ou em combinação com outro antimicrobiano. SCOARIs et al. (2008) observaram que 18 de 23 Aeromonas isoladas a partir de água mineral apresentaram múltipla resistência a três ou mais antibióticos testados, tendo a ampicilina $91 \%$ de resistência e a ciprofloxacina $100 \%$ de sensibilidade.

As populações bacterianas são heterogêneas, cada uma com sua própria sensibilidade a determinado antimicrobiano. O uso de antimicrobianos exerce pressão seletiva sobre elas e o uso de concentrações reduzidas das drogas eliminou as subpopulações mais sensíveis, levando ao crescimento excessivo da subpopulações menos sensíveis (GuARDABASSI et al., 2010).

\section{Resistência aos metais pesados}

Um dos principais problemas ambientais é a contaminação de águas por metais como $\mathrm{Cd}, \mathrm{Zn}$, $\mathrm{Cu}, \mathrm{Pb}, \mathrm{Ni}, \mathrm{Hg}$ e Co (Diels et al., 2003). Atividades industriais e agrícolas podem liberar metais tóxicos no ambiente, constituindo um grave perigo para o ecossistema, bem como à saúde humana. Em muitos sistemas aquáticos, resíduos de metais contaminantes são de grande significância, ocasionado em 
parte pelas atividades industriais e de mineradoras (MAtyar et al., 2009).

A grande contaminação do meio ambiente com metais funciona como agente seletivo na proliferação de resistência a antibióticos. Diferentes níveis e tipos de contaminações por metais sugerem mecanismos no processo de co-seleção dessa resistência (BAKERAustin et al., 2006).

Hassenetal.(1998) observaramcepasdePseudomonas que apresentavam resistência a metais pesados $(\mathrm{Cu}$, $\mathrm{Zn}, \mathrm{Cr}, \mathrm{Cd}, \mathrm{CoeHg}$ ), tendo alta concentração mínima inibitória e largo espectro de resistência antibiótica, concluindo que a $P$. aeruginosa pode ser utilizada como modelo para estudos ecotoxicológicos.

Akinbowale et al. (2007) determinaram alta resistência de isolados de Pseudomonas spp.e Aeromonas spp. frente a sete metais pesados $(\mathrm{Cu}, \mathrm{Pb}, \mathrm{Cr}, \mathrm{Mn}$, $\mathrm{Zn}, \mathrm{Cd}, \mathrm{Co}$ ), por meio do método de Concentração Inibitória Mínima (CIM). PATHAK; Gopal (2005) avaliaram a CIM visando a identificar a resistência de bactérias isoladas de peixes frente a metais pesados $(\mathrm{Cu}, \mathrm{Pb}, \mathrm{Mn}, \mathrm{Cd}$ e $\mathrm{Cr}$ ) , sendo evidenciada a tolerância em diferentes concentrações, com máxima para o manganês e mínima para o cromo.

O cromo é um metal largamente utilizado em processos industriais têxteis e curtumes, quando liberado no meio aquático acaba se depositando também nos peixes, dessa maneira as atividades celulares apresentam-se alteradas e os patógenos de peixes passam a ter alta resistência quando desafiados de forma crônica pelo cromo (STEINHAGEN et al., 2004).

MATYAR et al. (2009) avaliaram a sensibilidade de Aeromonas spp. e Pseudomas spp. frente a 15 antibióticos e seis metais pesados ( $\mathrm{Cd}$. $\mathrm{Cu}, \mathrm{Cr}, \mathrm{Pb}$, Mn e Zn), sendo observado um elevado índice de resistência dos micro-organismos, sugerindo que as bactérias tenham a capacidade de transferência do gene de resistência via plasmídeos. A presença de plasmídeos e a sua transferência entre as bactérias proporcionam a estes micro-organismos uma transferência de caracteres essências à sua sobrevida como, por exemplo, os plasmídeos responsáveis pela resistência antimicrobiana, degradação de metais pesados, ou mesmo aqueles que codificam toxinas bacterianas (ADAMs et al., 1998).

\section{Mecanismogenético de transmissão deresistência}

A transferência de genes entre as bactérias foi primeiramente descrita por Griffth em 1928, em estudos de virulência de pneumococos em camundongos. Muitos dos genes adquiridos desta forma podem carrear informações deletérias às bactérias receptoras, reduzindo sua população, outras informações são neutras, enquanto que algumas conferem uma vantagem seletiva aos micro-organismos, ou são carreadas por vetores que tem sua própria maquinaria de manutenção com potencial para se disseminar rapidamente numa população bacteriana (THOMAs; NiELSEN, 2005). Os plasmídeos podem carrear genes com diferentes funções: como fatores de virulência, adesinas e toxinas, resistência a metais pesados e genes de metabolismo de substratos incomuns (SHERLEY et al., 2004).

Embora alguns pesquisadores acreditem que a resistência somente ocorra após o uso das drogas antimicrobianas, a grande diversidade dos genes envolvidos atribui uma origem antiga. Esta resistência pode ser devida provavelmente para proteção de compostos antibióticos produzidos por organismos do meio ambiente com Streptomices spp., ou mutações de genes housekeeping (Dcosta et al., 2006). Uma nova teoria propõe que os antibióticos possuem um duplo papel no meio ambiente e, além da inibição de crescimento, bem estudada no meio acadêmico e clínico, estes seriam importantes como moléculas sinalizadoras podendo interagir com DNA do próprio micro-organismo como de seus vizinhos (FAJARDO; MARTìnEZ, 2008). Este papel se torna claro quando se avaliam outros compostos antimicrobianos não clássicos como as bacteriocinas, bem como pela relação entre quorum sensing e a produção de compostos antimicrobianos por bactérias como a Burkholderia thailandensis (FAJARDO; MARTİNEZ, 2008; DuERKop et al., 2009).

$\mathrm{O}$ ambiente aquático costuma reunir a água de ambientes próximos e com isto aproximar microorganismos de diferentes origens (SEnGELøv; SøRENSEN, 1998). O incremento no número de relatos da multirresistência entre isolados de ambientes aquáticos, como a Aeromonas spp., consideradas patógenos oportunistas e emergentes de peixes e humanos, tem sido observado em todo o mundo. Isto pode ser atribuído à transferência horizontal de elementos genéticos móveis, como plasmídeos e integrons (Ploy et al., 2000; LEVERSTEIN-VAN-HALL et al., 2002).

A conjugação envolve a troca de DNA por plasmídeos via a formação de pili sexual ou F. A pili comunica o citoplasma de duas células e permite tanto a passagem de plasmídeos, como de segmentos de DNA cromossomal. Os integrons são pequenos plasmídeos que utilizam os maiores para a sua replicação e transmissão, enquanto que os transposons são sequências de DNA de replicação e transmissão autônoma. Estas duas moléculas são muito importantes para o desenvolvimento de resistência múltipla as drogas antimicrobianas (SHERLEY et al., 2004). Plasmídeos contendo determinantes para resistências múltiplas aos antimicrobianos podem potencialmente transmitir essas características das bactérias dos peixes aos seres humanos, o que tem sido reportado para tetraciclina (RoDHEs et al., 2000). Vários plasmídeos e transposons têm sido 
encontrados em associação nos isolados clínicos e ambientais de Aeromonas spp. (RodHes et al., 2000; JACOBS; CHENIA, 2007), sendo descrita ainda a associação dos integrons com resistência múltipla aos antimicrobianos (LeVERSTEIN-VAN-HaLl et al., 2002). A conjugação via plasmídeos éconsiderada importante no solo e ambiente aquático (Trevors et al., 1987). No ambiente aquático a troca de plasmídeos entre bactérias de famílias diferentes pode ocorrer, o que explica a existência de bactérias multirresistentes em ambientes onde não exista uma grande pressão de seleção (KRUSE; SøRUM, 1994).

A transformação é um processo pelo qual o DNA é captado diretamente do ambiente de onde a bactéria reside (solos, plantas, animais, outros micro-organismos). Este processojá foi comprovado para organismos patogênicos e ambientais como E. coli, Pseudomonas spp. e Acinetobacter spp. (BAUR et al., 1996; VRIES et al., 2001). DNA puro pode ser obtido de diferentes fontes como solo, fezes, água, silagem, saliva humana, alimentos e rações (THOMAs; NieLSEN, 2005).

A identificação de vários genes de resistência antibiótica (Tabela 1) (ČížEK et al. 2010; IsHIDA et al., 2010; VERNER-JEFFREYs et al.2009) em Aeromonas spp. evidencia o risco dessas bactérias servir como reservatório desses genes, que podem ser transferidos para outras bactérias na aquicultura (JACOBS; CHENIA, 2007). Múltiplos mecanismos de resistência antimicrobiana tornam-se uma ameaça à saúde pública, bem como se fazem necessários tratamentos mais onerosos (IsHIDA et al., 2010).

\section{Considerações finais}

A contaminação de sistemas de produção pesqueira, peixes, meio ambiente, água e alimentos constitui potencial veículo de infecções causadas por Aeromonas spp. Salientam-se ainda os diversos mecanismos de virulência e resistência que podem ser transferidos para outros indivíduos com potencial patogênico.

O uso indiscriminado e não autorizado de antimicrobianos é um fator agravante na seleção de bactérias resistentes, bem como a contaminação do meio ambiente por dejetos hospitalares eindustriais.
É de fundamental importância a sensibilização dos piscicultores com relação ao uso racional de antimicrobianos, bem como de toda a população com o descarte do lixo e a preservação do meio ambiente, visto que a contaminação dos rios e lagos por metais e dejetos tem sido um dos fatores de grande importância para a co-seleção de bactérias resistentes.

\section{REFERÊNCIAS}

ABDULLAH, A.I.; HART, C.A.; WINSTANLEY, C. Molecular characterization and distribution of virulence associated genes amongst Aeromonas isolates from Libya. Journal of Applied Microbiology, v.95, p.1001-1007, 2003.

ADAMS, C.A.; AUSTIN, B.; MEADEN, P.G.; McINTOSH, D. Molecular Characterization of PlasmidMediated Oxytetracycline Resistance in Aeromonas salmonicida. Applied and Environmental Microbiology, v.64, n.11, p.4194-4201, 1998.

AGUILERA-ARREOLA, M.; HERNÁNDEZ-RODRÍGUEZ, C. H.; CASTRO-ESCARPULLI, G. Molecular and phenotypic characterization of A. hydrophila-like HG3 isolated of an infant with diarrhea in Mexico. Bioquimica, v.34, n.4, p.183-189, 2009.

AKINBOWALE, O.L.; PENG, H.; GRANT, P.; BARTON, M.D. Antibiotic and heavy metal resistance in motile aeromonads and pseudomonads from rainbow trout (Oncorhynchus mykiss) farms in Australia. International Journal of Antimicrobial Agents, v.30, p.177-182, 2007.

ALTWEGG, M.; GEISS, H. K. Aeromonas as a human pathogen. Critical Reviews in Microbiology, v.16, n.4, p.253-286, 1989.

BAKER-AUSTIN, C.; WRIGHT, M. S.; STEPANAUSKAS, R.; McARTHUR, J. V. Co-selection of antibiotic and metal resistance. Trends in Microbiology, v.14, n.4, p.176-182, 2006.

BAUR, B., HANSELMANN, K., SCHLIMME, W., JENNI, B. Genetic transformation in freshwater: Escherichia coli is able to develop natural competence. Applied and Environmental Microbiology, v.62, p.3673-3678,1996.

Tabela 1 - Integron/gene que confere resistência a antimicrobianos descritos em isolados do gênero Aeromonas.

\begin{tabular}{lcl}
\hline Antimicrobiano & Integron/gene resistência & Referência \\
\hline Tetraciclina & Tet & Č́žEK et al. (2010) \\
Streptomicina & Aad & IsHIDA et al. $(2010)$ \\
Trimetoprim & Dfr & IsHIDA et al. (2010) \\
Cloranfenicol & Cat & IsHIDA et al. $(2010)$ \\
Quinolona/Fluorquinolona & Qnr & VERNER-JEFFREYs et al. (2009) \\
Florfenicol & Flor & IsHIDA et al. $(2010)$ \\
Betalactamases & Bla & VERNER-JEFFREY et al. (2009) \\
\hline
\end{tabular}


BEAZ-HIDALGO, R.; ALPERI, A.; BUJÁN, N.; ROMALDE, J.L.; FIGUEIRAS, M.J. Comparison of phenotypical and genetic identification of Aeromonas strains isolated from diseased fish. Systematic and Applied Microbiology, v.33, p.149-153, 2010.

BIZANI, D.; BRANDELLI, A. Antimicrobial susceptibility, hemolysis, and emagglutination among Aeromonas spp. isolated from water of a bovine abattoir. Brazilian Journal of Microbiology, v.32, p.334-339, 2001.

BORRELL, N.; ACINAS, S. G.; FIGUEIRAS, M. J.; MURCIA, A. J. M. Identification of Aeromonas Clinical Isolates by Restriction Fragment Length Polymorphism of PCR-Amplified 16S rRNA Genes. Journal of Clinical Microbiology, v.35, n.7, p.1671-1674, 1997.

CASCÓN, A.; ANGUITA, J.; HERNANZ, C.; SÁNCHEZ, M.; FERNÁNDEZ, M.; NAHARRO, G. Identification of Aeromonas hydrophila hybridization group 1 by PCR assays. Applied and Environmental Microbiology, v.62, n.4, p.1167-1170, 1996.

CASTRO-ESCARPULLI, G.; FIGUEIRAS, M. J.; AGUILERA-ARREOLA, G.; SOLER, L.; FERNÁNDEZRENDÓN, E.; APARICIO, G. O.; GUARRO, J.; CHACÓN, M. R. Characterisation of Aeromonas spp. isolated from frozen fish intended for human consumption in Mexico. International Journal of Food Microbiology, v.84, p.41-49, 2003.

CHOPRA, A.K.; HOUSTON, C.W. Enterotoxins in Aeromonas-associated gastroenteritis. Microbes and Infection, v.1, n.13, p.1129-1137, 1999.

ČÍŽEK, A.; DOLEJSKÁ, M.; SOCHOROVÁ, R.; STRACHOTOVÁ, K.; PIAČKOVÁ, V.; VESELÝ, T. Antimicrobial resistance and its genetic determinants in Aeromonads isolated in ornamental (koi) carp (Cyprinus carpio koi) and common carp (Cyprinus carpio). Veterinary Microbiology, v.142, n.3/4, p.435-439, 2010.

COLWELL, R. R.; MACDONELL, M. T.; LEY, J. Proposal to Recognize the Family Aeromonadaceae fam. nov. International Journal of Systematic Bacteriology, v.36, n.3, p.473-477, 1986.

DCOSTA, V.M., MCGRAM, K.M., HUGHES, D.W., WRIGTH, G.D. Sampling the antibiotic resistome. Science, v.311, n.5759, p.374-377, 2006.

DIELS, L.; SPAANS, P. H.; ROY, S. V.; HOOYBERGHS, L.; RYNGAERT, A.; WOUTERS, H.; WALTER, E.; WINTERS, J.; MACASKIE, M. L.; FINLAY, J.; PERNFUSS, B.; WOEBKING, H.; PUMPEL, T.; TSEZOS, M. Heavy Metals removal by sand filters inoculated with metal sorbing and precipitating bacteria. Hidrometallurgy, v.71, p.235-241, 2003.

DUERKOP, B.A.; VARGA, J.; CHANDLER, J.R.; PETERSON, S.B.; HERMAN, J.P.; CHURCHILL, M.E.A.; PARSEK, M.R., NIERMAN, W.C.; GREENBERG, E.B.
Quorum-Sensing control of antibiotic synthesis in Burkholderia thailandensis. Journal of Bacteriology, v.191, n.12, p.3909-3918, 2009.

EVANGELISTA-BARRETO, N.S.; CARVALHO, F.C.T.; VIEIRA, R.H.S.F., REIS, C.M.F.; MACRAE, A.; RODRIGUES, D.P. Characterization of Aeromonas species isolated from an estuarine environment. Brazilian Journal Microbiology, v.41, n.2, p.452-460, 2010.

FAJARDO, A.; MARTÍNEZ, J.L. Antibiotics as signals that trigger specific bacterial responses. Current Opinion in Microbiology, v.11, p.161-167, 2008.

FOOD AND DRUG ADMINISTRATION (US). Bad bug book: foodborne pathogenic microorganisms and natural toxins handbook. 1.ed. [Chapter:] Aeromonas hydrophila.[ data Disponível em: <http://www.fda.gov/Food/FoodSafety/FoodborneIllness/FoodborneIllnessFoodbornePathogensNaturalToxins/BadBugBook/ucm070523. htm>. Acesso em: 8 nov.2010.

FRAPPAOLA, P.J.; GUEST, G.B. Regulatory status of tetracyclines, penicillin and other antibacterial drugs in animal feeds. Journal Animal Science, v.62, p.86-92, 1986.

GHATAK, S.; AGARWAL, R.K.; BHILEGAONKAR, K.N. Species identification of clinically important Aeromonas spp. by restriction fragment length polymorphism of $16 \mathrm{~S}$ rDNA. Letters in Applied Microbiology, v.44, p.550-554, 2007.

GHENGHESH, K.S.; AHMED, S.F.; EL-KHALEK, R.A.; AL-GENDY, A.; KLENA, J. Aeromonas-associated infections in developing countries. Journal Infect Developing Countries, v.2, n.2, p.81-98, 2008.

GRAM, L.; MELCHIORSEN, J.; SPANGGAARD, B.; HUBER, I.; NIELSEN, T. F. Inhibition of Vibrio anguillarum by Pseudomonas fluorescens $\mathrm{AH} 2$, a possible probiotic treatment of fish. Applied and Environmental Microbiology, v.65, n.3, p.969-973, 1999.

GUARDABASSI, L.; JENSEN, L.B.; KRUSE, H. Guia de antimicrobianos em veterinária. Porto Alegre: Artmed, 2010. 267p.

GUERRA, I.M.F.; FADENELLI, R.; FIGUEIRÓ, M.; SCHREINER, F.; DELAMARE, A.P.L.; WOLLHEIM, C.; COSTA, S.O.P.; ECHEVERRIGARAY, S. Aeromonas associated diarrhoeal disease in south Brazil: prevalence, virulence factors and antimicrobial resistance. Brazilian Journal of Microbiology, v.38, n.4, p.638-643, 2007.

HASSEN, A.; SAIDI, N.; CHERIF, M.; BOUDABOUS, A. Effects of heavy metals on Pseudomonas aeruginosa and Bacillus thuringiensis. Bioresource Technology, v.65, n.1/2, p.73-82, 1998.

ISHIDA Y.; AHMED, A.M.; MAHFOUZ, N.B.; KIMURA, T.; EL-KHODERY, S.A.; MOAWAD, A.A.; SHIMA- 
MOTO, T. Molecular analysis of antimicrobial resistance in Gram-negative bacteria isolated from fish farms in Egypt. Journal of Veterinary Medical Science, v.72, n.6, p.727-734, 2010.

JACOBS, L.; CHENIA, H.Y. Characterization of ntegrons and tetracycline resistance determinants in Aeromonas spp. isolated from South African aquaculture systems. International Journal of Food Microbiology, v.114, p.295-306, 2007.

KINGOMBE, C.I.B.; D'AOUST, J.; HUYS, G.; HOFMANN, L.; RAO, M.; KWAN, J. Multiplex PCR method for detection of three Aeromonas enterotoxin genes. Applied and Environmental Microbiology, v.76, n.2, p.425-433, 2010.

KRUSE, H.; SØRUM, H. Transfer of multiple drug resistance plasmids between bacteria of diverse origins in natural microenvironments. Applied and Environmental Microbiology, v.60, n.11, p.4015-4021, 1994.

LEVERSTEIN-VAN-HALL, M.A.; PAAUW, A.; BOX, A.T.A.; BLOK, H.E.M.; VERHOEF, J.; FLUIT, A.C. Presence of integron-associated resistance in the community is widespread and contributes to multidrug resistance in the hospital. Journal of Clinical Microbiology, v.40, n.8, p.3038-3040, 2002.

MATYAR, F.; AKKAN T.; UÇAK, Y.; ERASLAN, B. Aeromonas and Pseudomonas: antibiotic and heavy metal resistance species from Iskenderun Bay, Turkey (northeast Mediterranean Sea). Environmental Monitoring Assessment, v.167, p.309-320, 2009.

MEJDI, S.; EMIRA, N.; ALI, M.; HAFEDH, H.; AMINA, $B$. Biochemical characteristics and genetic diversity of Vibrio spp. and Aeromonas hydrophila strains isolated from the Lac of Bizerte (Tunisia). World Journal of Microbiology \& Biotechnology, v.26, p.2037-2046, 2010.

NAM, I.Y.; JOH, K. Rapid detection of virulence of Aeromonas isolated from a trout by hexaplex-PCR. Journal of Microbiology, v.45, n.4, p.297-304, 2007.

NAWAZ, M.; SUNG, K.; KHAN, S.A.; KHAN, A.A.; STEELE, R. Biochemical and molecular characterization of tetracycline-resistant Aeromonas veronii isolates from Catfish. Applied and Environmental Microbiology, v.72, n.10, p.6461-6466, 2006.

NIHAL, Y.; SEDA, E. Virulence properties and characterization of Aeromonas isolated from foods of animal origin and environmental sources. Journal of Food Protection, v.73, n.5, p.855-860, 2010.

PATHAK, S.P.; GOPAL, K. Occurrence of antibiotic and metal resistance in bacteria from organs of river fish. Environmental Research, v.98, p.100-103, 2005.

PAVANELLI, G.C.; EIRAS, J.C.; TAKEMOTO, R.M. Doenças de peixes: profilaxia, diagnóstico e tratamento. 3.ed. Maringá: Eduem, 2008. 311p.
PIDDOCK, L.J.V. Clinically relevant chromosomally encoded multidrug resistance effl ux pumps in bacterial. Clinical Microbiology Reviews, v.19 p.382-402, 2006.

PLOY, M.; LAMBERT, T.; COUTY, J.; DENIS, F. Integrons: an antibiotic resistance gene capture and expression system. Clinical and Chemistry Laboratory Medicine, v.38, p.483-487, 2000.

RALL, V.L.M.; IARIA, S.T.; HEIDTMANN, S.; PIMENTA, F.C.; GAMBA, R.C.; PEDROSO, D.M.M. Aeromonas species isolated from pintado fish (Pseudoplatystoma sp.): virulence factors and drug susceptibility. Revista de Microbiologia, v.29, n.3, p.222-227, 1998.

RHODES, G.; HUYS, G.; SWINGS, J.; MEGANN, P.; HINEY, M.; SMITH, P.; PICKUP, R. W. Distribution of oxytetracycline resistance plasmids between aeromonads in hospital and aquaculture environments: Implication of Tn/721 in dissemination of the tetracycline resistance determinant Tet A. Aplied and Environmental Microbiology, v.66, p.3883-3890, 2000.

SCOARIS, D.O.; COLACITE, J.; NAKAMURA, C.V.; UEDA-NAKAMURA, T.; ABREU FILHO, B.A.; DIAS FILHO, B.P. Virulence and antibiotic susceptibility of Aeromonas spp. isolated from drinking water. Antonie van Leeuwenhock, v.93, p.111-122, 2008.

SEN, K.; RODGERS, M. Distribution of six virulence factors in Aeromonas species isolated from US drinking water utilities: a PCR identification. Journal of Applied Microbiology, v.97, p.1077-1086, 2004.

SENGELØV, G.; SØRENSEN, S. J. Methods for detection of conjugative plasmid transfer in aquatic environments. Current Microbiology, v.37, p.274-280, 1998.

SHERLEY, M.; GRODON, D.M.; COLLIGNON, P.J. Evolution of multi-resistance plasmids in Australian clinical isolates of Escherichia coli. Microbiology, v.150, p.1539-1546, 2004.

SMITH, P. R.; BRETON, A. L.; HORSBERG, T. E.; CORSIN, F. Guidelines for antimicrobial use in aquaculture. In: GUARDABASSI, L.; JENSEN, L. B.; KRUSE, H. (Ed.). Guide to antimicrobial use in animals. Oxford: WilleyBlackwell, 2008. p.207-216.

STEINHAGEN, D.; HELMUS, T.; MAURER, S.; MICHAEL, R.D.; LEIBOLD, W.; SCHARSACK, J.P.; SKOURAS, A.; SCHUBERTH, H. Effect of hexavalent carcinogenic chromium on carp Cyprinus carpio immune cells. Diseases of Aquatic Organisms, v.62, p.155-161, 2004.

THOMAS, C.M.; NIELSEN, K.M. Mechanisms of, and barriers to, horizontal gene transfer between bacteria. Nature Reviews, v.3, p.711-721, 2005.

TRABULSI, L.R.; ALTERTHUM, F. Microbiologia. 4.ed. São Paulo: Atheneu, 2004. 718p. 
TREVORS, J.T.; BARKAY, T.; BOURQUIN, A.W. Gene Transfer among bacteria in soil and aquatic environments: a review. Canadian Journal of Microbiology, v.33, p.191-198, 1987.

VERNER-JEFFREYS, D.W.; WELCH, T.J.; SCHWARZ, T.; POND, M.J.; WOODWARD, M.J.; HAIG, S.J.; RIMMER, G.S.; ROBERTS, E.; MORRISON, V.; C-BAKER,

A. High prevalence of multidrug-tolerant bacteria and associated antimicrobial resistance genes isolated from ornamental fish and their carriage water.PLoS ONE, v.4, n.12, p.2194-2206, 2009.

VERSCHUERE, L.; ROMBAUT, G.; SORGELOOS, P.; VERSTRAETE. W. Probiotic Bacteria as Biological Control Agents in Aquaculture. Microbiology and Molecular Biology Reviews, v.64, n.4, p.655-671, 2000.

VRIES, B.J.; MEIER, P.; WACKERNAGEL, W. The natural transformation on the soil bacteria Pseudomonas stuzeri and Acinetobacter sp. by transgenic plant DNA strictly dependes on homologous sequences in the recipient cells. FEMS Microbiology Letters, v.195, p.211215, 2001.

WONG, C.Y.F.; HEUZENROEDER, M.W.; FLOWER, R.L.P. Inactivation of two haemolytic toxin genes in Aeromonas hidrophila attenuates virulence in a suckling mouse model. Microbiology, v.144, p.291-298, 1998.

YATES, C.M.; PEARCE, M.C.; WOOHOUSE, M.E.J.; AMYES,S.G.B. High frequency transfer and horizontal spread of apramycin resistance in calf faecal Escherichia coli. Journal of Antimicrobial Chemotherapy, v.54, n.2, p.534-537, 2004.

Recebido em 25/4/11

Aceito em 2/7/12 